\title{
A highly efficient polyampholyte hydrogel sorbent based fixed-bed process for heavy metal removal in actual industrial effluent
}

\author{
Guiyin Zhou ${ }^{a}$, Jinming Luo ${ }^{b}$, Chengbin Liu ${ }^{a,}{ }^{*}$, Lin Chu ${ }^{a}$, Jianhong Ma ${ }^{c}$, Yanhong Tang ${ }^{d}$, \\ Zebing Zeng a, Shenglian Luo ${ }^{\text {a, ** }}$ \\ a State Key Laboratory of Chemo/Biosensing and Chemometrics, Hunan University, Changsha 410082, PR China \\ ${ }^{\mathrm{b}}$ Key Laboratory of Drinking Water Science and Technology, Research Center for Eco-Environmental Sciences, Chinese Academy of Sciences, Beijing 100085, \\ China \\ ${ }^{c}$ College of Environmental Science and Engineering, Hunan University, Changsha 410082, PR China \\ ' College of Materials Science and Engineering, Hunan University, Changsha 410082, PR China
}

\section{A R T I C L E I N F O}

\section{Article history:}

Received 9 July 2015

Received in revised form 19 November 2015

Accepted 22 November 2015

Available online 2 December 2015

\section{Keywords:}

Polyampholyte hydrogel

Heavy metal removal

Actual wastewater

Fixed-bed process

Treatment capacity

\begin{abstract}
A B S T R A C T
High sorption capacity, high sorption rate, and fast separation and regeneration for qualified sorbents used in removing heavy metals from wastewater are urgently needed. In this study, a polyampholyte hydrogel was well designed and prepared via a simple radical polymerization procedure. Due to the remarkable mechanical strength, the three-dimensional polyampholyte hydrogel could be fast separated, easily regenerated and highly reused. The sorption capacities were as high as $216.1 \mathrm{mg} / \mathrm{g}$ for $\mathrm{Pb}(\mathrm{II})$ and $153.8 \mathrm{mg} / \mathrm{g}$ for $\mathrm{Cd}$ (II) owing to the existence of the large number of active groups. The adsorption could be conducted in a wide $\mathrm{pH}$ range of 3-6 and the equilibrium fast reached in 30 min due to its excellent water penetration for highly accessible to metal ions. The fixed-bed column sorption results indicated that the polyampholyte hydrogel was particularly effective in removing $\mathrm{Pb}(\mathrm{II})$ and $\mathrm{Cd}(\mathrm{II})$ from actual industrial effluent to meet the regulatory requirements. The treatment volumes of actual smelting effluent using one fixed bed column were as high as 684 bed volumes (BV) (7736 mL) for $\mathrm{Pb}$ (II) and 200 BV $(2262 \mathrm{~mL})$ for $\mathrm{Cd}(\mathrm{II})$. Furthermore, the treatment volumes of actual smelting effluent using tandem three columns reached $924 \mathrm{BV}(31,351 \mathrm{~mL})$ for $\mathrm{Pb}(\mathrm{II})$ and $250 \mathrm{BV}(8483 \mathrm{~mL})$ for $\mathrm{Cd}(\mathrm{II})$, producing only 4 BV (136 mL) eluent. Compared with the traditional high density slurry (HDS) process with large amount of sludge, the proposed process would be expected to produce only a small amount of sludge. When the treatment volume was controlled below $209.3 \mathrm{BV}(7103 \mathrm{~mL})$, all metal ions in the actual industrial effluent could be effectively removed $(<0.01 \mathrm{mg} / \mathrm{L})$. This wok develops a highly practical process based on polyampholyte hydrogel sorbents for the removal of heavy metal ions from practical wastewater.
\end{abstract}

๑) 2015 Elsevier Ltd. All rights reserved.

\section{Introduction}

Heavy metal wastewater is the current outstanding problem in the field of water pollution. Due to the high toxicity and nonbiodegradability of heavy metals (Liu et al., 2013), it is very urgent to seek effective methods to remove heavy metals from wastewater (Bian et al., 2012). Various treatment technologies have been applied for the removal of toxic metal ions pollutants from wastewater, including ion exchange, filtration, chemical

\footnotetext{
* Corresponding author.

** Corresponding author.

E-mail addresses: chem_cbliu@hnu.edu.cn (C. Liu), sllou@hnu.edu.cn (S. Luo).
}

precipitation, solvent extraction, sorption and so on (Jin et al., 2014a). Although various techniques for the removal of toxic metal ions have been developed, sorption is considered a facile effective technique due to its cost-effective, versatile and simple to operate for removing trace-levels metal ions from aqueous systems (Ali, 2012).

Recently, the research on adsorbents for the removal of toxic metal ions has been focused on nanomaterial-based adsorbents which possess large surface areas, easy modification, and large number of active sites for binding metal ions (Sun et al., 2013b). Still, the separation and reusability of nanomaterials is a tedious job (Ali, 2012), and the residual nanomaterials in water will undoubtedly bring new security concerns as well (Lowry et al., 2012; Zhao et al., 2014). Therefore, the adsorbents with good separation and 
regeneration properties show incomparable advantages over nanomaterial-based adsorbents. Bulk materials used as sorbents are in favor of separation, but the low adsorption capacity and slow adsorption rate of them is a real problem (Cao et al., 2012).

Hydrogel, a three-dimensional cross-linked network of polymers, exhibits a distinctive feature of high swelling in water (Wang et al., 2010b). They have been considered as a type of mechanically weak materials (Calvert, 2009), and thus little attention is focused on them as possible structural materials. Recently several tough hydrogels with good mechanical properties, such as doublenetwork hydrogels (Sun et al., 2012; Chen et al., 2013; Nakajima et al., 2012), polyampholyte hydrogels (Sun et al., 2013a), and hydrogel composites (Huang et al., 2007), have revealed the potential as structural materials (Shibayama, 2012). Among these hydrogels, polyampholyte hydrogels bear randomly dispersed cationic and anionic repeat groups, forming tough and viscoelastic hydrogels with multiple mechanical properties. Also, the supramolecular structure of polyampholyte hydrogels can be tuned to change multiple function properties over wide ranges by diverse functional unit combinations (Sun et al., 2013a). Additionally, excellent water penetration of hydrogel is highly accessible to foreign molecules (Kudaibergenov and Ciferri, 2007). This uniqueness of polyampholyte hydrogel motivates us to exploit this kind of materials as adsorbents for removing heavy metals in water. To our knowledge, there is no report about sorbents based on polyampholyte hydrogel.

This study presents a novel polyampholyte hydrogel strengthened with graphene oxide, which also provided a framework for the formation of 3D structure. This polyampholyte hydrogel possesses some advantages: good mechanical property for easy separation and durable recycling, large amount of carboxyl and amino groups for high sorption capacity, and high swelling for fast sorption. As a result, the polyampholyte hydrogel as adsorbents was successfully used in the treatment of actual industrial wastewater. The experimental parameters of the adsorption characteristics, fixed-bed column sorption and regeneration/recycling tests were investigated. This work is expected to potentially develop a step change in adsorbent materials for removing heavy metal ions in wastewater.

\section{Materials and methods}

\subsection{Materials}

Graphene oxide (GO) was prepared by oxidation of natural graphite powder (320 mesh, Qingdao Tianhe Graphite Co. Ltd) according to a modified improved Hummers' method (Marcano et al., 2010). Acrylic acid (AA) and methyl methacrylate (MMA) were distilled under reduced pressure before use. Ammonium persulfate (APS), N,N-methylenebisacrylamide (MBA), N,N, $\mathrm{N}^{\prime}, \mathrm{N}^{\prime}$-tetramethylethylenediamine (TEMED), sodium dodecylsulfonate (SDS) and triethylene tetramine (TETA) were purchased from commercial sources and used as received. The actual industrial effluent was taken from Shuikoushan smelting plant located in Hengyang, Hunan province, China. All aqueous solutions were prepared with deionized water.

\subsection{Preparation of polyampholyte hydrogel}

Polyampholyte hydrogel was synthesized using radical copolymerization and functionalized by aminolysis reaction. In a typical preparation procedure of polyampholyte hydrogel, the radical copolymerization of AA $(0.4 \mathrm{~mL})$ and MMA $(0.2 \mathrm{~mL})$ was initiated by APS $(0.003 \mathrm{~g})$ in $2 \mathrm{~mL}$ of $5 \mathrm{mg} / \mathrm{mL} \mathrm{GO}$ aqueous suspension, using MBA $(0.012 \mathrm{~g})$ as crosslinking agents, TEMED $(5 \mu \mathrm{L})$ as the crosslinking accelerator and SDS (0.2 g) as emulsifying agent. The reaction last for $2 \mathrm{~h}$ at $60{ }^{\circ} \mathrm{C}$ to get a hydrogel product. Then the hydrogel was immersed into $10 \mathrm{~mL}$ of $0.1 \mathrm{~g} / \mathrm{mL}$ TETA aqueous solution for $2 \mathrm{~h}$ at $90^{\circ} \mathrm{C}$ to complete the ammonolysis of methyl ester. At last, the polyampholyte hydrogel was washed with deionized water to remove SDS and unreacted reagents. The cost of the polyampholyte hydrogel production is approximately US\$ $6.3 \times 10^{3} / \mathrm{t}$, much lower than those of some reported sorbent materials (see Supporting Information).

\subsection{Characterization}

The structure of the polyampholyte hydrogel was examined by scanning electron microscopy (SEM, FEI QUANTA 200). The functional groups in the hydrogel were characterized by Fourier transform infrared spectra (FTIR, Nicolet 5700) and Raman spectra (Labram-010). The $\mathrm{N}$ and $\mathrm{O}$ contents of the samples were determined by an elementary analysis (vario EL III). The thermogravimetric analysis (TGA, TG/DTA7300) was measured under a nitrogen atmosphere from room temperature to $700{ }^{\circ} \mathrm{C}$ with heating rate of $10^{\circ} \mathrm{C} / \mathrm{min}$. The surface chemistry properties of the hydrogel during the adsorption process were determined by X-ray photoelectron spectroscopy (XPS, K-Alpha 1063, Thermo Fisher Scientific, England). The compression test of the hydrogel was performed on a universal testing machine (HZ-1007C) with compression/decompression rate of $1 \mathrm{~mm} / \mathrm{min}$. The $\mathrm{pH}$ values at the point of zero charge ( $\mathrm{pH}$ PZC $)$ of the hydrogel were measured in a series of $0.01 \mathrm{M}$ $\mathrm{NaCl}$ with different initial $\mathrm{pH}$. The swelling experiment was performed by immersing the hydrogel in an excess of water at room temperature to reach swelling equilibrium. The swelling ratio $(S R)$ of the hydrogel was calculated as $S R=\left(W_{\mathrm{s}}-W_{\mathrm{d}}\right) / W_{\mathrm{d}}$, where $W_{\mathrm{s}}$ and $W_{\mathrm{d}}$ represent the weights of swollen hydrogel and dry hydrogel, respectively.

\subsection{Batch adsorption experiments}

Batch adsorption experiments were conducted to explore the adsorption properties and mechanism of the polyampholyte hydrogel which was swollen with deionized water before adsorption. The sorbent dosage was calculated by the weight of dry hydrogel. Analytical grade $\mathrm{Pb}\left(\mathrm{NO}_{3}\right)_{2}$ and $\mathrm{Cd}\left(\mathrm{NO}_{3}\right)_{2}$ were employed to prepare the $\mathrm{Pb}$ (II) and $\mathrm{Cd}(\mathrm{II})$ stock solutions. The $\mathrm{pH}$ values of the solution were adjusted by $0.1 \mathrm{M} \mathrm{HCl}$ or $\mathrm{NaOH}$ solutions, and $\mathrm{NaClO}_{4}$ or $\mathrm{LiClO}_{4}$ were added as background electrolyte. The concentrations of residuary metal ions in solution were measured by an atomic absorption spectrometer (AAS, Hitachi Z-2000, Japan). The metaladsorbed hydrogel was eluted with $0.1 \mathrm{M} \mathrm{HCl}$ solution, then regenerated with $0.1 \mathrm{M} \mathrm{NaOH}$ solution, and washed with deionized water to neutral. All the experimental data were the average of triplicate determinations with less than $5 \%$ relative errors.

\subsection{Fixed-bed column sorption experimental}

Fixed-bed column sorption experiments were carried out at ambient temperature using the polyampholyte hydrogel $(2 \mathrm{~mm} \times 2 \mathrm{~mm} \times 2 \mathrm{~mm})$ packed in fixed-bed columns. Two feeding solutions (FS) with different metal concentration were treated: FS1 (simulated effluent) contains $40 \mathrm{mg} / \mathrm{L} \mathrm{Pb}, \mathrm{Cd}, \mathrm{Ca}, \mathrm{Mg}, \mathrm{Na}$ and $\mathrm{K}$ or FS2 (actual industrial effluent) contains $2.225 \mathrm{mg} / \mathrm{L} \mathrm{Pb}, 4.175 \mathrm{mg} / \mathrm{L}$ Cd, $203.7 \mathrm{mg} / \mathrm{L} \mathrm{Zn,} 14.75 \mathrm{mg} / \mathrm{L} \mathrm{Mn}, 4.675 \mathrm{mg} / \mathrm{L} \mathrm{Ni}, 9.675 \mathrm{mg} / \mathrm{L} \mathrm{Cu}$, $0.042 \mathrm{mg} / \mathrm{L} \mathrm{Cr}$ and $10.02 \mathrm{mg} / \mathrm{L}$ Fe. The FS was pumped down-flow through the column by a peristaltic pump. A hydrochloric acid $(\mathrm{HCl})$ solution with an upper concentration limit of $0.1 \mathrm{M}$ was used as the eluting agent for desorption. The column parameters are summarized in Table 1. 
Table 1

The fixed-bed column parameters.

\begin{tabular}{ll}
\hline Parameter & Column \\
\hline Mass of dry sorbent & $3 \mathrm{~g}$ \\
Column diameter & $12 \mathrm{~mm}$ \\
Bed depth & $100 \mathrm{~mm}$ \\
Flow rate & $2.26 \mathrm{~mL} / \mathrm{min}$ \\
Hydraulic loading rate & $20 \mathrm{~mm} / \mathrm{min}$ \\
Bed volume (BV) & $11.31 \mathrm{~mL}$ for one column \\
& $33.93 \mathrm{~mL}$ for three columns \\
Empty bed contact time (EBCT) & $5 \mathrm{~min}$ for one column \\
& $15 \mathrm{~min}$ for three columns \\
\hline
\end{tabular}

The amounts of metal ions adsorbed were calculated from the difference between the initial concentration $\left(C_{0}\right)$ and equilibrium concentration $\left(C_{\mathrm{e}}\right)$. Sorption\% $=\left(C_{0}-C_{\mathrm{e}}\right) / C_{0} \times 100 \%, q_{\mathrm{e}}=V \times$ $\left(C_{0}-C_{\mathrm{e}}\right) / \mathrm{m}$, and $K_{\mathrm{d}}=V \times\left(C_{0}-C_{\mathrm{e}}\right) /\left(C_{\mathrm{e}} \times m\right)$, where $q_{\mathrm{e}}(\mathrm{mg} / \mathrm{g})$ is the metal ions adsorbed quantity at equilibrium, $V$ is the volume of the suspension, $m$ is the mass of dry polyampholyte hydrogel, and $K_{\mathrm{d}}$ $(\mathrm{mL} / \mathrm{mg})$ is the distribution coefficient.

\section{Results and discussion}

\subsection{Characterization of polyampholyte hydrogel}

The polyampholyte hydrogel shows a massive texture (inset in Fig. 1a). Obviously, the massive materials are in favor of fast separation from water. The SEM image of the polyampholyte hydrogel reveals a loose and porous structure (Fig. 1a). The interpenetrating network channels are accessible to foreign molecules including metal ions. The good mechanical strength is demanded for a qualified sorbent. The recovery or fatigue resistant behavior of the polyampholyte hydrogel was investigated by consecutive loading-unloading tests with gradually increasing compressive strain
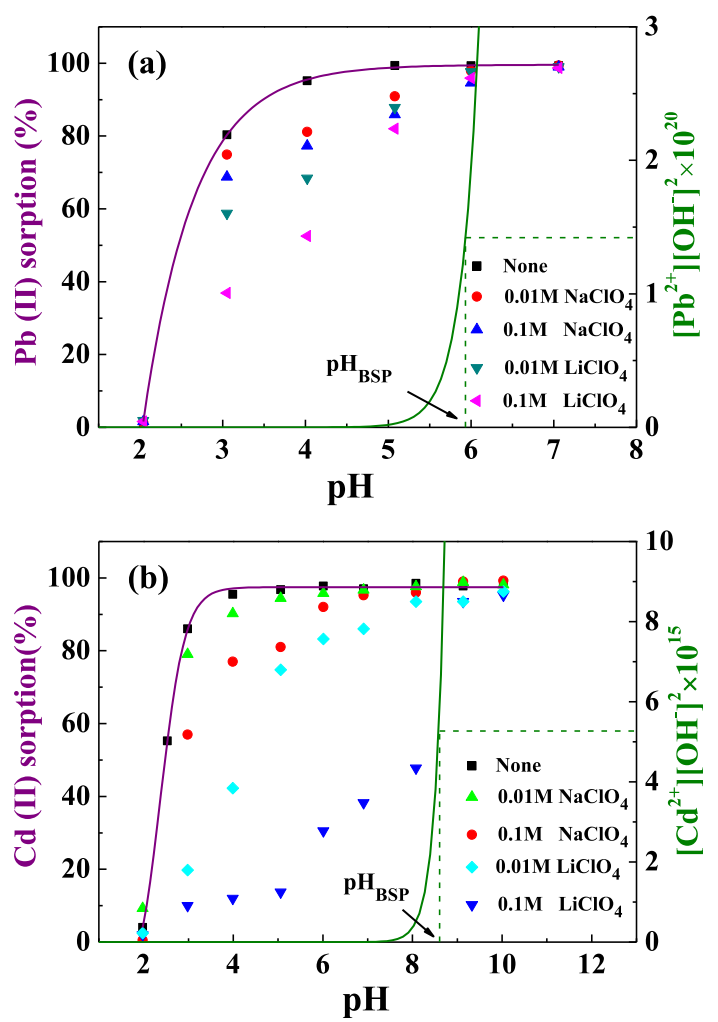

Fig. 2. Effect of $\mathrm{pH}$ and ionic strength on $\mathrm{Pb}(\mathrm{II})(\mathrm{a})$ and $\mathrm{Cd}(\mathrm{II})$ (b) adsorption onto polyampholyte hydrogel: $C_{0 \mathrm{~Pb}(\mathrm{II})}=C_{0 \mathrm{Cd}(\mathrm{II})}=40 \mathrm{mg} / \mathrm{L}, t_{\text {contact }}=2 \mathrm{~h}, \mathrm{~m} / \mathrm{V}=1 \mathrm{~g} / \mathrm{L}$, and $\mathrm{T}=303 \mathrm{~K}$.
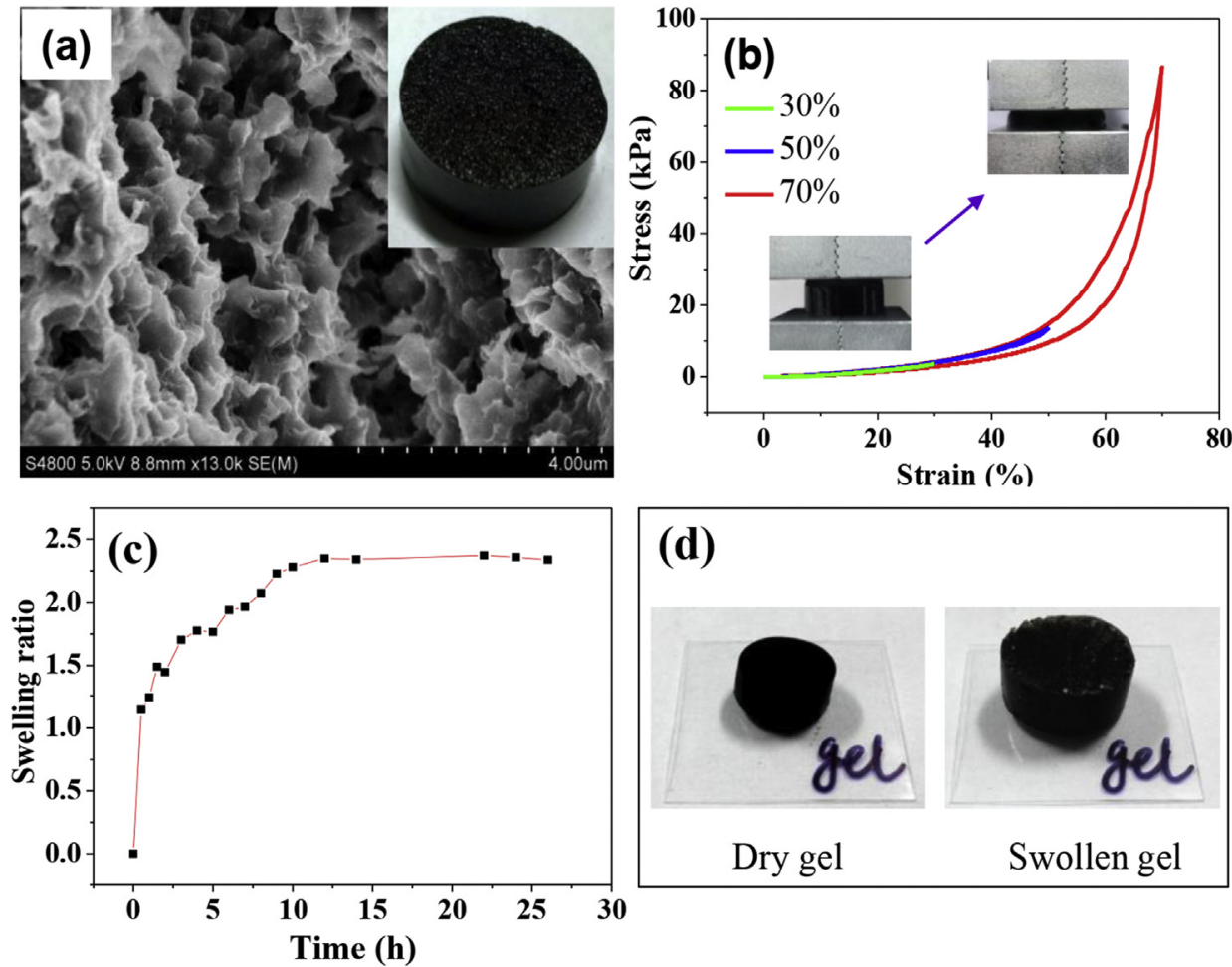

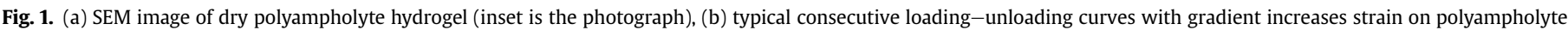
hydrogel, (c) dynamic swelling profiles of the polyampholyte hydrogel, and (d) the photographs of dry and swollen hydrogel (swelling for $12 \mathrm{~h}$ ). 


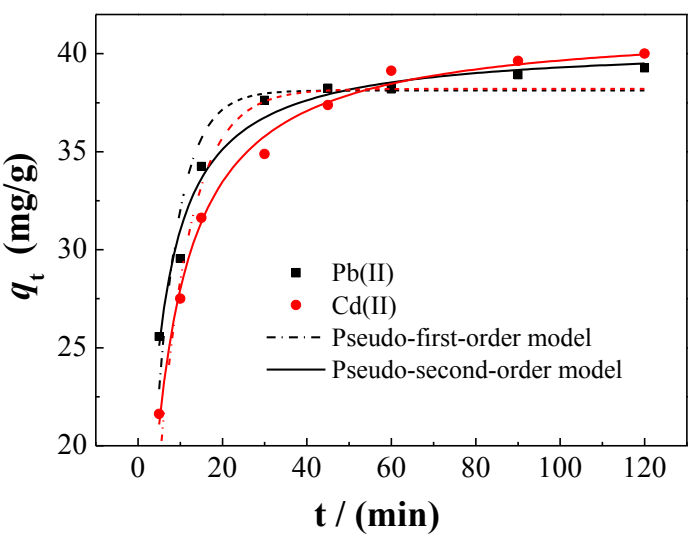

Fig. 3. Time-dependent $\mathrm{Pb}(\mathrm{II})$ and $\mathrm{Cd}(\mathrm{II})$ sorption on polyampholyte hydrogel: $\mathrm{pH}=5.0$ for $\mathrm{Pb}(\mathrm{II})$ and 6.0 for $\mathrm{Cd}(\mathrm{II}), \mathrm{T}=303 \mathrm{~K}, C_{0}=40 \mathrm{mg} / \mathrm{L}$, and $\mathrm{m} / \mathrm{V}=1 \mathrm{~g} / \mathrm{L}$.

( $\varepsilon$ ) from $30 \%$ to $50 \%$, and $70 \%$. Fig. 1b shows typical compress stress-strain curves of hydrogel at different stretching rates. The overlapping of subsequent loading and unloading curves $(\varepsilon=30 \%$ and $50 \%$ ) uncovers that the hydrogel effectively dissipates energy, avoiding the structural damage (Du et al., 2014). After the immediate third cycle $(\varepsilon=70 \%)$, the polyampholyte hydrogel still recovers its original shape and size almost completely after unloading the stress, even though the hysteresis phenomena appears. The good mechanical property of the polyampholyte hydrogel should owe to the fact that the randomness of charges forms multiple ionic bonds with a wide distribution of strengths, through interchain and intrachain complexation (Sun et al., 2013a; Xu et al., 2015; Yin et al., 2013). Moreover, the GO sheets act as chemical crosslinking points in the polyampholyte hydrogel through amination reaction between the epoxy groups of GO and the amino groups in TETA (see the FTIR results shown below). The synergy of GO sheets bridging by the network of covalent crosslinks and hysteresis by unzipping the network of ionic crosslinks endows hydrogel with good tenacity and mechanical strength. The oxygen and nitrogen in the polyampholyte hydrogel are $24.51 \%$ and $5.96 \%$, respectively, determined by elemental analysis. The swelling ratio is an important parameter for hydrogels to be used in metal ion sorption. High permeability can promote metal ion mobility into the hydrogel that allows them to reach adsorption equilibrium rapidly (Mawad et al., 2012). The swelling behavior of the polyampholyte hydrogel is shown in Fig. 1c and $d$. The swelling ratios of the hydrogel in water increase with time until reaching equilibrium at around $12 \mathrm{~h}$ and the swelling ratio (SR) value is about 2.3 . The swollen polyampholyte hydrogel has a supramolecular structure, containing about $70 \mathrm{wt} \%$ of water at an equilibrium state.

To investigate possible structure and chemical composition of the polyampholyte hydrogel, the Fourier transform infrared (FTIR) spectra of GO, PAA, PMMA, TETA and polyampholyte hydrogel were analyzed (Fig. S1 in Supporting Information). The polyampholyte hydrogel displays the stretching vibrations of $\mathrm{C}=\mathrm{O}$ and $\mathrm{C}-\mathrm{O}$ from GO, PAA and PMMA at $1729 \mathrm{~cm}^{-1}$ and $1380 \mathrm{~cm}^{-1}$, respectively. The $\mathrm{C}-\mathrm{H}$ stretching vibrations for TETA, PMMA and polyampholyte
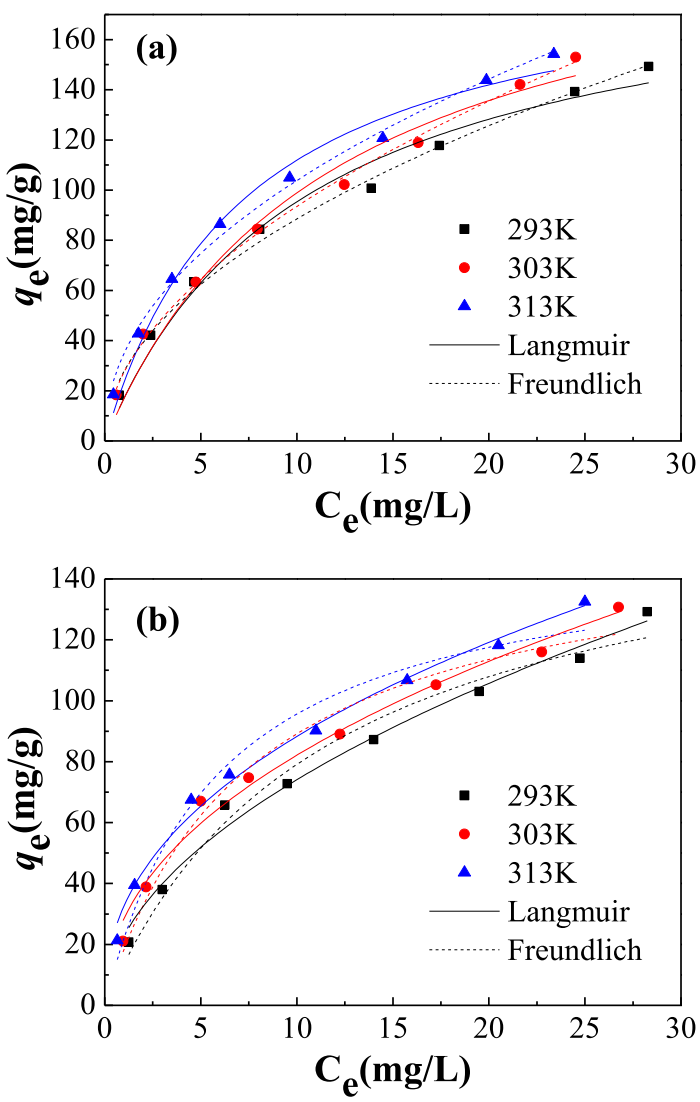

Fig. 4. Sorption isotherms of $\mathrm{Pb}(\mathrm{II})$ (a) and $\mathrm{Cd}(\mathrm{II})$ (b) on polyampholyte hydrogel at different temperatures: $\mathrm{pH}=5.0$ for $\mathrm{Pb}(\mathrm{II})$ and 6.0 for $\mathrm{Cd}(\mathrm{II}), t_{\text {contact }}=2 \mathrm{~h}$, and $\mathrm{m} /$ $\mathrm{V}=1 \mathrm{~g} / \mathrm{L}$.

hydrogel are found at $2950 \mathrm{~cm}^{-1}$. The $\mathrm{N}-\mathrm{H}$ deformation and stretching vibrations for both TETA and polyampholyte hydrogel are detected at $1567 \mathrm{~cm}^{-1}$ and $3000-3650 \mathrm{~cm}^{-1}$, whereas the $-\mathrm{OH}$ group of the polyampholyte hydrogel could be overlapped due to a rather broad band in this region (Liu et al., 2012). Meanwhile, the Raman spectra furthermore confirm the existence of GO in the polyampholyte hydrogel (Fig. S2).

The thermogravimetric analysis (TGA) of the samples is shown in Fig. S3. The weight loss of samples in the first step up to $150{ }^{\circ} \mathrm{C}$ can be due to the loss of moisture. The major weight losses of GO between $150{ }^{\circ} \mathrm{C}$ and $300{ }^{\circ} \mathrm{C}$, correspond to $\mathrm{CO}_{2}, \mathrm{CO}$ and steam release from the most labile functional groups (Marcano et al., 2010; Zhao et al., 2011). The two mass loss stages of PMMA are observed up to $260{ }^{\circ} \mathrm{C}$ and $340{ }^{\circ} \mathrm{C}$, which are attributed to the degradation of the ester group and the depolymerization of polymer and formation of a carbonaceous residue (Gonçalves et al., 2010). The thermal degradation of PAA occurs in the range from 240 to $450{ }^{\circ} \mathrm{C}$ due to the pyrolysis of carboxyl, subsequently, breaking of the polymer backbone. The polyampholyte hydrogel clearly shows two pyrolysis stages, which would result from the sum of the individual materials. The thermostability of the hydrogel

Table 2

Constants for the kinetic sorption data using different sorption models.

\begin{tabular}{|c|c|c|c|c|c|c|c|}
\hline \multirow[t]{2}{*}{ Metals } & \multirow[t]{2}{*}{$q_{\mathrm{e}, \exp }(\mathrm{mg} / \mathrm{g})$} & \multicolumn{3}{|c|}{ Pseudo-first-order } & \multicolumn{3}{|c|}{ Pseudo-second-order } \\
\hline & & $k_{1}(\mathrm{~L} / \mathrm{min})$ & $q_{\mathrm{e}, \text { cal }}(\mathrm{mg} / \mathrm{g})$ & $\mathrm{R}^{2}$ & $k_{2}(\mathrm{~g} /(\mathrm{mg} \cdot \mathrm{min}))$ & $q_{\mathrm{e}, \mathrm{cal}}(\mathrm{mg} / \mathrm{g})$ & $\mathrm{R}^{2}$ \\
\hline $\mathrm{Pb}$ & 39.68 & 0.1833 & 38.12 & 0.8861 & 0.0081 & 40.51 & 0.9754 \\
\hline $\mathrm{Cd}$ & 40.37 & 0.1363 & 38.21 & 0.9051 & 0.0049 & 41.58 & 0.9928 \\
\hline
\end{tabular}


Table 3

Comparison of the maximum uptake of $\mathrm{Pb}(\mathrm{II})$ and $\mathrm{Cd}(\mathrm{II})$ on various adsorbents.

\begin{tabular}{|c|c|c|c|c|}
\hline \multirow[t]{2}{*}{ Adsorbent } & \multirow[t]{2}{*}{ Solution conditions } & \multicolumn{2}{|c|}{$q_{\max }(\mathrm{mg} / \mathrm{g})$} & \multirow[t]{2}{*}{ Refs } \\
\hline & & $\mathrm{Pb}(\mathrm{II})$ & $\mathrm{Cd}(\mathrm{II})$ & \\
\hline Mesoporous titania beads & $\mathrm{pH}=5.9, \mathrm{~T}=298 \mathrm{~K}$ & & 8.9 & Wu et al., 2012 \\
\hline Magnetic hydrogels & $\mathrm{pH}=7, \mathrm{~T}=298 \mathrm{~K}$ & 126.4 & 130.9 & Ozay et al., 2009 \\
\hline Amino functionalized graphene & $\mathrm{pH}=6, \mathrm{~T}=313 \mathrm{~K}$ & 27.9 & 27.8 & Guo et al., 2014 \\
\hline Graphene nanosheets & $\mathrm{pH}=4.0, \mathrm{~T}=303 \mathrm{~K}$ & 22.4 & & Huang et al., 2011 \\
\hline Carbon nanotube sheets & $\mathrm{pH}=7.0, \mathrm{~T}=298 \mathrm{~K}$ & 117.6 & 92.5 & Tofighy and Mohammadi, 2011 \\
\hline Magnetic Xanthate/chitosan & $\mathrm{pH}=5.0, \mathrm{~T}=298 \mathrm{~K}$ & 76.9 & 34.5 & Zhu et al., 2012 \\
\hline Mercapto functionalized sepiolite & $\mathrm{T}=298 \mathrm{~K}$ & 116.3 & 34.8 & Liang et al., 2011 \\
\hline Activated carbon & $\mathrm{pH}=5, \mathrm{~T}=298 \mathrm{~K}$ & 98.4 & & Wang et al., 2010a \\
\hline Polyampholyte hydrogel & $\mathrm{pH}=5$ for $\mathrm{Pb}, \mathrm{pH}=6$ for $\mathrm{Cd}, \mathrm{T}=313 \mathrm{~K}$ & 216.1 & 153.8 & This work \\
\hline
\end{tabular}

is enough for a sorbent.

\subsection{Effect of environmental conditions}

The environmental conditions affect the solubility and the ionization degree of the adsorbates, as well as the surface charge of the adsorbent, consequently influencing the removal of metal ions from aqueous solution. To evaluate the effect of environmental conditions on the adsorption of $\mathrm{Pb}(\mathrm{II})$ and $\mathrm{Cd}(\mathrm{II})$ on the polyampholyte hydrogel, a series of adsorption experiments including the effect of $\mathrm{pH}$, ionic strength and foreign ions were conducted. The sorption results of $\mathrm{Pb}(\mathrm{II})$ and $\mathrm{Cd}(\mathrm{II})$ on the polyampholyte hydrogel as a function of $\mathrm{pH}$ are shown in Fig. 2. The sorption of $\mathrm{Pb}$ (II) without the foreign ions increases quickly at pHs ranging from 2 to 3, then increases slowly at $\mathrm{pH} 3-5$, and at last retains the high sorption at $\mathrm{pH}$ above 6 . For $\mathrm{Cd}(\mathrm{II})$ without the foreign ions, the sorption of $\mathrm{Cd}(\mathrm{II})$ increases abruptly at $\mathrm{pH}$ from 2 to 4 , and then maintains high level at $\mathrm{pH}>4$. The $\mathrm{pH}$ value at zero potential point $\left(\mathrm{pH}_{\mathrm{pzc}}\right)$ of the polyampholyte hydrogel is 7.6 (Fig. S4). At $\mathrm{pH}<\mathrm{pH}_{\mathrm{pzc}}$, since the protonation reaction on the surfaces of the hydrogel, the electrostatic repulsion is against the sorption of the positive metal ions onto the positively charged surface of the hydrogel. Particularly, at low pH value below 2 , the positive metal ions are very difficult to adsorb on the positively charged surface of the hydrogel. Whereas, with increasing the $\mathrm{pH}$ (i.e., $\mathrm{pH} \mathrm{3-6),} \mathrm{the}$ protonation reaction becomes weak, so the carboxyl groups may conduct ion exchange with heavy metal ions directly to form metal complexes (Wu and Li, 2013). Moreover, amino groups work in compleximetric mode, where metal ions are chelated forming a coordinate-type interaction (Gurgel and Gil, 2009; Zhou et al., 2015). At $\mathrm{pH}>\mathrm{pH}_{\mathrm{pzc}}$, adsorption surfaces becomes deprotonated, which will make for the metal ion adsorption. However, when $\mathrm{pH}$ value increases above the $\mathrm{pH}$ of bulk solution precipitation $\left(\mathrm{pH}_{\mathrm{BSP}}\right)$, it would lead to the precipitation of heavy metal ions. The $\mathrm{pH}_{\mathrm{BSP}}$ for $\mathrm{Pb}(\mathrm{II})$ and $\mathrm{Cd}(\mathrm{II})$ with initial concentration of $40 \mathrm{mg} / \mathrm{L}$ are 5.94 and 8.62, respectively. According to solubility product constant, lower concentration of metal ions, the $\mathrm{pH}_{\mathrm{BSP}}$ will become higher. So the results disclose that the sorbent can be used in a wide $\mathrm{pH}$ range of 3-6 to effectively simultaneously remove $\mathrm{Pb}(\mathrm{II})$ and $\mathrm{Cd}(\mathrm{II})$. Conversely, desorption of $\mathrm{Pb}(\mathrm{II})$ and $\mathrm{Cd}(\mathrm{II})$ adsorbed on the hydrogel sorbents could be completed by elution process using acid solution with pH below 2 .

Fig. 2 also shows the effects of ionic strength $\left(\mathrm{Li}^{+}\right.$and $\left.\mathrm{Na}^{+}\right)$on $\mathrm{Pb}(\mathrm{II})$ and $\mathrm{Cd}(\mathrm{II})$ uptake by the polyampholyte hydrogel. The uptakes of both $\mathrm{Pb}(\mathrm{II})$ and $\mathrm{Cd}(\mathrm{II})$ decrease when increasing of $\mathrm{Li}^{+}$or $\mathrm{Na}^{+}$concentration from $0.01 \mathrm{M}$ to $0.1 \mathrm{M}$, which should result from the competition and electrostatic repulsion among alkali metal ions and from the lower activity coefficient of $\mathrm{Pb}(\mathrm{II})$ or $\mathrm{Cd}(\mathrm{II})$ at higher ionic strength (Jin et al., 2014b). The ionic strength affects the interface potential and thickness of the double layer between the background solution and the surface of sorbents, influencing the binding of the adsorbing species (Li et al., 2012). The background ions are placed in the same plane as the outer-sphere complexes, which generally occur in ion exchange process (Tamura et al., 2014). Consequently, the sorption of $\mathrm{Pb}(\mathrm{II})$ and $\mathrm{Cd}(\mathrm{II})$ suggest that the adsorption mechanisms may be the combined action of ion exchange and complexation. Additionally, $\mathrm{Li}^{+}$ions show greater influence than $\mathrm{Na}^{+}$ions, probably due to the smaller ion radius of $\mathrm{Li}^{+}$ which would lead to stronger reaction between $\mathrm{Li}^{+}$ions and adsorption sites.

\subsection{Adsorption kinetics}

Adsorption kinetics is important in the prediction of the rate at which $\mathrm{Pb}(\mathrm{II})$ and $\mathrm{Cd}(\mathrm{II})$ can be removed by the polyampholyte hydrogel. The effect of time on the adsorption is presented in Fig. 3. The sorptions of $\mathrm{Pb}(\mathrm{II})$ or $\mathrm{Cd}(\mathrm{II})$ on the polyampholyte hydrogel increase rapidly in the first $30 \mathrm{~min}$ and reach adsorption equilibrium in approximately $30 \mathrm{~min}$ and $60 \mathrm{~min}$, respectively. For bulk material-based sorbents, the sorption rate is very fast, even better than that of most common nonmaterial sorbents. Obviously, the excellent sorption rate should owe to the three-dimensional loose and porous structure and its excellent water penetration of polyampholyte hydrogel which is highly accessible to metal ions. The fast adsorption kinetics meets the requirement of the treatment of heavy metal wastewater.

To analyze the sorption rate of $\mathrm{Pb}(\mathrm{II})$ and $\mathrm{Cd}(\mathrm{II})$ on the polyampholyte hydrogel, the pseudo-first-order (Eq. (1)) and the pseudo-second-order (Eq. (2)) models were used to describe the sorption kinetic data.

$q_{t}=q_{e}\left(1-\exp \left(-k_{1} t\right)\right)$

$q_{t}=q_{e}\left(1-\frac{1}{1+q_{e} k_{2} t}\right)$

where $q_{\mathrm{t}}$ and $q_{\mathrm{e}}(\mathrm{mg} / \mathrm{g})$ are the amounts of metal ions adsorbed onto the polyampholyte hydrogel at time and at equilibrium, respectively, and $k_{1}(\mathrm{~L} / \mathrm{min})$ and $k_{2}(\mathrm{~g} /(\mathrm{mg} \cdot \mathrm{min}))$ are the corresponding adsorption rate constants. The values of the kinetics constants are shown in Table 2. It is found that the correlation coefficients $\left(\mathrm{R}^{2}\right)$ of the modeled pseudo-second-order by experiment data of $\mathrm{Pb}(\mathrm{II})$ and $\mathrm{Cd}(\mathrm{II})$ are above 0.97 , larger than those of the modeled pseudo-first-order, which proves that the sorption kinetics of $\mathrm{Pb}(\mathrm{II})$ and $\mathrm{Cd}(\mathrm{II})$ on the sorbent are well described by pseudo-second-order rate equation. In general, the pseudo-secondorder model is superior for describing practical experimental data (Luo et al., 2014b). 

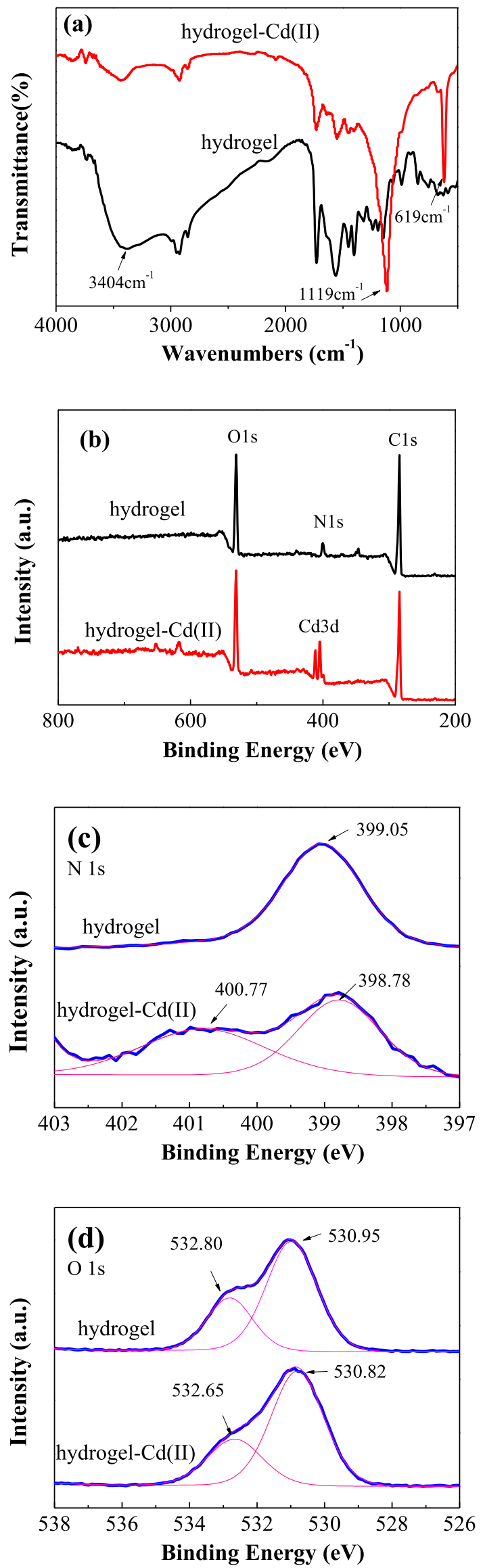

\subsection{Adsorption modeling and thermodynamics}

The adsorption isotherms describe the interactive behavior between adsorbent and solutes, which have been simulated by applying the well-established fundamental models. It is a routine method to obtain the parameters via the application of the linear regression statistical analysis of the models. Nonetheless, since linearization can be only applied to two-component models and itself creates significant error (Hadi et al., 2013), in this study, a nonlinear curve fit approach was used to evaluate the fit of the isotherm model to the experimental data and the fitting parameters are summarized in Table S1. According to the correlation coefficient $\mathrm{R}^{2}$ results, all except the Temkin model well describe the metal ions adsorption onto the polyampholyte hydrogel using the parameters obtained. Interestingly, the $\mathrm{R}^{2}$ of the Langmuir-Freundlich, RP and Toth, extension of the Langmuir model, are better than that of the Langmuir, implying that the sorption process might be the combined action of chemical adsorption and electrostatic attraction. The ability of the Langmuir and Freundlich model to approximate the experimental adsorption data for $\mathrm{Pb}(\mathrm{II})$ and $\mathrm{Cd}(\mathrm{II})$ is illustrated in Fig. 4. From the results of fitting parameters based on the Langmuir model, the polyampholyte hydrogel has the potential to remove $\mathrm{Pb}(\mathrm{II})$ and $\mathrm{Cd}(\mathrm{II})$ from aqueous solutions with a maximum adsorption capacity of 216.1 and $153.8 \mathrm{mg} / \mathrm{g}$, respectively. Table 3 lists $\mathrm{Pb}(\mathrm{II})$ and $\mathrm{Cd}(\mathrm{II})$ adsorption capacities of the polyampholyte hydrogel and other adsorbents, including some commonly used adsorbing materials, artificial synthetic materials and newly developed nanomaterials. Although a direct comparison among different sorbents is demanding and inaccurate because of the differences of sorbent characters and experimental conditions, the high adsorption capacity of the polyampholyte hydrogel still reveals that the polyampholyte hydrogel could be considered to have a great potential in dealing with practical heavy metal wastewater.

The thermodynamic parameters such as the standard free energy change $(\Delta G)$, standard enthalpy change $(\Delta H)$, and standard entropy changes $(\Delta S)$ were also calculated according to the van't Hoff equation (Table S2). The negative value of $\Delta G$ and the positive value of $\Delta H$ confirm that the process is essentially a spontaneous and endothermic one. In general, metal ions are well solvated in aqueous solution, the hydration sheath of metal ions has to be destroyed before its sorption, and this dehydration process needs energy (Genç-Fuhrman et al., 2004). Meanwhile, the positive $\Delta S$ value suggests an increased randomness at the hydrogel/solution surface, which could arise from the release of water molecules from the hydration sheath and/or from the displacement of two $\mathrm{Na}^{+}$or $\mathrm{H}^{+}$ions from the hydrogel for each divalent cation adsorbed.

\subsection{Adsorption mechanism}

A basic understanding of the adsorption mechanisms between heavy metal ions and adsorbent is essential to evaluate environmental behaviors. Generally, the heavy metal ions are removed by adsorbent via ion exchange, complexation and precipitation. In the above discussion, a preliminary conclusion can be inferred that this adsorption process includes ion exchange and complexation. To further determine the interaction mechanism, the FTIR and XPS study were performed by choosing $\mathrm{Cd}(\mathrm{II})$ sorption as a representative case.

Fig. 5a shows the FTIR spectra of the polyampholyte hydrogel

Fig. 5. FTIR spectra (a), total survey scan of XPS spectra (b), and high-resolution XPS spectra of N1s (c) and 01s (d) of polyampholyte hydrogel before and after adsorption of $\mathrm{Cd}(\mathrm{II})$. 
before and after adsorption of $\mathrm{Cd}(\mathrm{II})$. The $\mathrm{N}-\mathrm{H}$ and $-\mathrm{COOH}$ stretching vibration peaks at $3000-3650 \mathrm{~cm}^{-1}$ in the polyampholyte hydrogel without Cd(II) adsorption mostly disappear after $\mathrm{Cd}(\mathrm{II})$ adsorption while two new peaks appear at fingerprint region where the peak at $619 \mathrm{~cm}^{-1}$ corresponds to the stretching vibration of $\mathrm{Cd}-\mathrm{N}$ bond (Gurgel and Gil, 2009) and the other peak at $1119 \mathrm{~cm}^{-1}$ is probably attributed to the association of the carboxylate group with $\mathrm{Cd}(\mathrm{II})$ ions, indicating that the attachment of $\mathrm{Cd}(\mathrm{II})$ on the $-\mathrm{NH}_{2}$ and $-\mathrm{COOH}$ groups. The significant changes reveal the complex formation between $\mathrm{Cd}$ and $\mathrm{N}$ atoms and the ionic bond formation between $-\mathrm{COO}^{-}$and $\mathrm{Cd}^{2+}$.

In order to further understand the adsorption mechanism, XPS analysis was also applied to characterize the changes of functional groups before and after adsorption. In the total XPS survey scans (Fig. 5b), in addition to the characteristic peaks of C1s (284 eV), N1s (399 eV) and O1s (531 eV) for the polyampholyte hydrogel, the peaks of Cd3d ( 405 and $411 \mathrm{eV}$ ) are obviously observed in the Cdadsorbed hydrogel. Fig. $5 \mathrm{c}$ and d show the high-resolution XPS results. Fig. $5 \mathrm{c}$ illustrates that before adsorption, there is only one typical $\mathrm{N} 1 \mathrm{~s}$ peak at $399.05 \mathrm{eV}$ from the $\mathrm{N}$ atom in $-\mathrm{NH}_{2}$ groups of the hydrogel while after the adsorption of $\mathrm{Cd}(\mathrm{II})$, in addition to the peak of $-\mathrm{NH}_{2}$ at around $398.78 \mathrm{eV}$, a new peak of N1s appears at $400.77 \mathrm{eV}$, which could be attributed to the formation of complexes between $\mathrm{N}$ and $\mathrm{Cd}$ (Wu and Li, 2013). After Cd uptake, the $\mathrm{N}$ atoms share the lone pair of electrons with $\mathrm{Cd}$, thereby reducing the electron densities of the $\mathrm{N}$ atoms with higher binding energy (Yang and Jiang, 2014). Meanwhile, in the high-resolution XPS spectrum of 01 s (Fig. 5d), there is no new peak observed after the $\mathrm{Cd}(\mathrm{II})$ adsorption, demonstrating that the interaction mechanism between $\mathrm{O}$ and $\mathrm{Cd}$ is not complexation as between $\mathrm{N}$ and $\mathrm{Cd}$, but the ion exchange between $-\mathrm{COOH}$ and $\mathrm{Cd}(\mathrm{II})$ (Luo et al., 2014a). Thus, the removal of $\mathrm{Cd}(\mathrm{II})$ by the polyampholyte hydrogel is not a single process, mainly controlled by the complexation between $-\mathrm{NH}_{2}$ and $\mathrm{Cd}(\mathrm{II})$ and the ion exchange between $-\mathrm{COOH}$ and $\mathrm{Cd}(\mathrm{II})$.

\subsection{Sorption/desorption, recyclability and selective adsorption test}

The regeneration and reusability of adsorbents is one of the most important features for practical applications. From any environmental point of view, the repetitive usage of sorbents provides clues for economic feasibility and resourcefulness. Due to the reversible sorption/desorption of $\mathrm{Pb}(\mathrm{II})$ and $\mathrm{Cd}(\mathrm{II})$ on the polyampholyte hydrogel according to the variation of $\mathrm{pH}$ value of solution, the regeneration of the sorbent is entirely possible. Five adsorption/desorption studies were performed for $\mathrm{Pb}(\mathrm{II})$ and $\mathrm{Cd}(\mathrm{II})$ on the polyampholyte hydrogel using $0.1 \mathrm{M} \mathrm{HCl}(\mathrm{pH}=1)$ solution as stripping agents (Fig. 6a). The $\mathrm{Pb}(\mathrm{II})$ and $\mathrm{Cd}$ (II) removal efficiencies in the first cycle are respectively $96.4 \%$ and $95.2 \%$ whereas the removal efficiencies in the third cycles slightly decrease to $93.5 \%$ and $91.5 \%$, respectively. Even in the fifth cycle, the removal efficiencies of $\mathrm{Pb}(\mathrm{II})$ and $\mathrm{Cd}(\mathrm{II})$ still reach $91.5 \%$ and $87.5 \%$, respectively. The gradual decrease in the removal efficiency could be attributed to incomplete release of adsorbed metal ions which occupy some adsorption sites although the desorption efficiencies of $\mathrm{Pb}$ (II) and $\mathrm{Cd}(\mathrm{II})$ in each cycle reach above $98.5 \%$. Thus it can be seen that the polyampholyte hydrogel possesses good recyclability, which is advantageous from the cost point of view and other environmental concerns such as disposal of spent adsorbents.

For a selective adsorption experiment, $20 \mathrm{~mL}$ of the mixed solution containing $\mathrm{Pb}(\mathrm{II}), \mathrm{Cd}(\mathrm{II}), \mathrm{Cu}(\mathrm{II}), \mathrm{Zn}(\mathrm{II}), \mathrm{Mn}(\mathrm{II})$ and $\mathrm{Ni}(\mathrm{II})$ was prepared, and all the heavy metal ions were set at $40 \mathrm{mg} / \mathrm{L}$. As shown in Fig. $6 \mathrm{~b}$, the uptakes of $\mathrm{Pb}(\mathrm{II})$ and $\mathrm{Cd}(\mathrm{II})$ ions, especially $\mathrm{Pb}(\mathrm{II})$, are higher than those of other metal ions. This may be caused by the difference of chelation ability (Yu et al., 2008), stability constant, electronegativity, size of hydrated ion, atomic weight, and
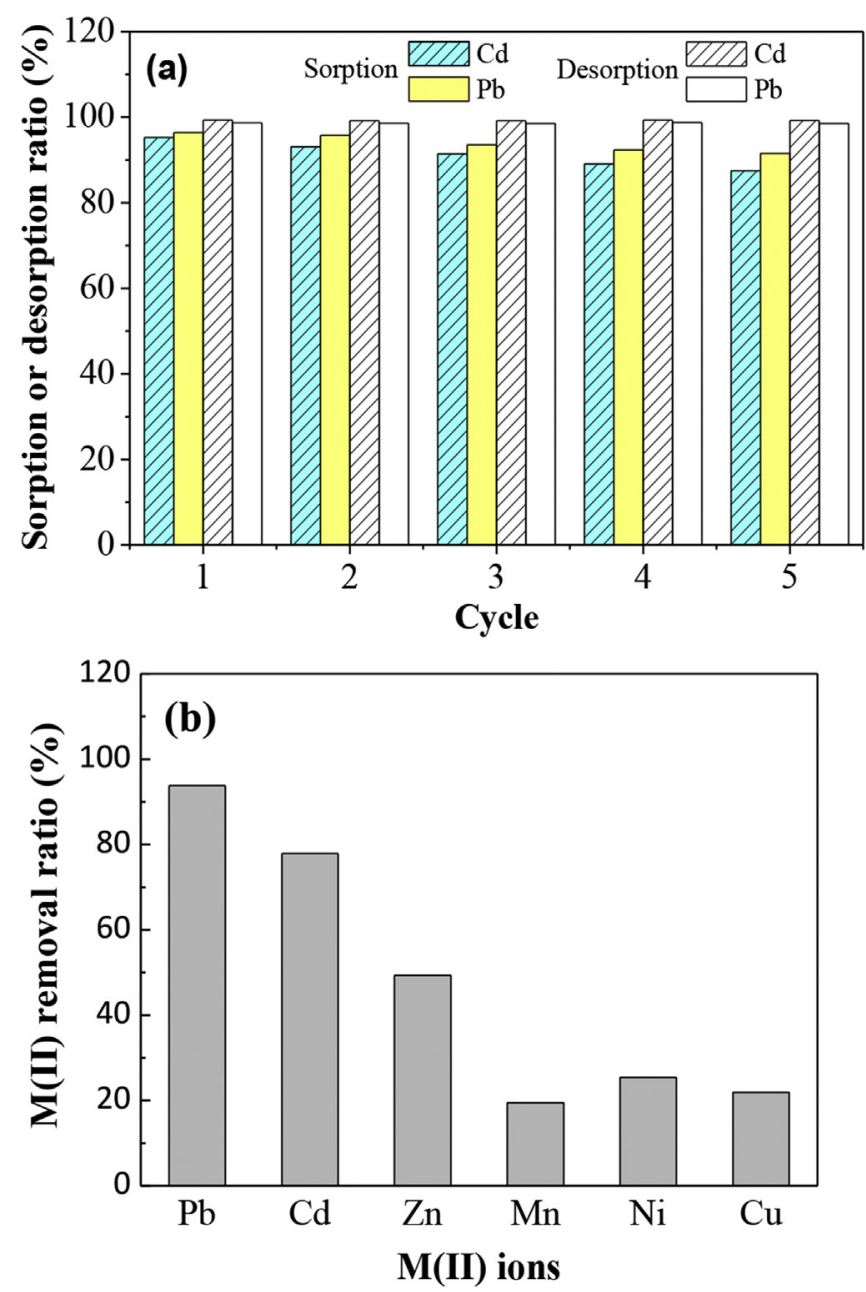

Fig. 6. (a) Recycling of the polyampholyte hydrogel in removal of $\mathrm{Pb}(\mathrm{II})$ and $\mathrm{Cd}(\mathrm{II})$ : $\mathrm{C}_{\text {initial }}=40 \mathrm{mg} / \mathrm{L}, \mathrm{pH}=5.0$ for $\mathrm{Pb}(\mathrm{II})$ and 6.0 for $\mathrm{Cd}(\mathrm{II})$, and (b) metal ions removal on the polyampholyte hydrogel from a mixed solution of metal ions: $C_{\text {initial }}=40 \mathrm{mg} / \mathrm{L}$, $\mathrm{pH}=5.0, \mathrm{~m} / \mathrm{V}=1 \mathrm{~g}$ dry gel $/ \mathrm{L}, \mathrm{T}=303 \mathrm{~K}$, and $t_{\text {contact }}=2 \mathrm{~h}$.

mass-to-charge ratio (Hadi et al., 2013; Dastgheib and Rockstraw, 2002) of metal ions, and preferential adsorption might happen in a competition environment.

\subsection{Treatment of actual industrial effluent}

In order to assess the feasibility of the polyampholyte hydrogel for removing heavy metal ions in actual wastewater, an actual industrial effluent provided by Shuikoushan smelting plant was tested for removal of heavy metals. The initial $\mathrm{pH}$ value of the industrial effluent was 2.8 , and the $\mathrm{pH}$ was adjusted to $5.0 \pm 0.1$ before being treated. The adsorption data of metal ions by different adsorbent dosage are summarized in Table 4. After treatment by $1 \mathrm{~g} / \mathrm{L}$ hydrogel, the $\mathrm{Pb}, \mathrm{Cr}$ and $\mathrm{Fe}$ are preferentially removed, probably due to the high average valence electron energy of $\mathrm{Cr}$ and $\mathrm{Fe}$, and higher electronegativity of $\mathrm{Pb}$ (Hadi et al., 2013). Meanwhile, the removal efficiency of Cd is only $74.1 \%$, which may be caused by the competition and electrostatic repulsion between the large amounts of other metal ions. When increasing adsorbent dosage to $2 \mathrm{~g} / \mathrm{L}$, the removal efficiencies of $\mathrm{Pb}$ and $\mathrm{Cd}$ reach 99.9 and $95.9 \%$, respectively. When further increasing adsorbent dosage to $4 \mathrm{~g} / \mathrm{L}$, the removal efficiencies are 99.9\% for $\mathrm{Cd}, 91.3 \%$ for $\mathrm{Zn}, 44.1 \%$ for $\mathrm{Mn}, 50.2 \%$ for $\mathrm{Ni}$ and $31 \%$ for $\mathrm{Cu}$. The results uncover that the polyampholyte hydrogel has a 
Table 4

Metal ions concentrations of industrial effluent before and after adsorption by different sorbent dosage.

\begin{tabular}{|c|c|c|c|c|c|c|c|c|c|}
\hline \multirow[t]{2}{*}{ Sorbent dosage $(\mathrm{g} / \mathrm{L})$} & \multirow[t]{2}{*}{$\mathrm{pH}$} & \multicolumn{8}{|c|}{ Metals concentration/(mg/L) } \\
\hline & & $\mathrm{Pb}$ & $\mathrm{Cd}$ & $\mathrm{Zn}$ & Mn & $\mathrm{Ni}$ & $\mathrm{Cu}$ & $\mathrm{Cr}$ & $\mathrm{Fe}$ \\
\hline 0 & 2.8 & 2.226 & 4.175 & 203.70 & 14.75 & 4.675 & 9.675 & 0.042 & 10.02 \\
\hline 1 & 5.0 & 0.007 & 1.080 & 120.37 & 13.25 & 4.225 & 8.925 & $<0.001$ & $<0.01$ \\
\hline 2 & 5.0 & $<0.001$ & 0.172 & 70.07 & 11.00 & 3.550 & 7.825 & $<0.001$ & $<0.01$ \\
\hline 3 & 5.0 & $<0.001$ & 0.028 & 44.15 & 10.25 & 2.750 & 7.725 & $<0.001$ & $<0.01$ \\
\hline 4 & 5.0 & $<0.001$ & $<0.001$ & 17.62 & 8.25 & 2.325 & 6.675 & $<0.001$ & $<0.01$ \\
\hline
\end{tabular}

great potential in the treatment of wastewater containing $\mathrm{Pb}(\mathrm{II})$ and $\mathrm{Cd}(\mathrm{II})$.

\subsection{Fixed-bed column sorption test}

Accurate prediction of target metal ions breakthrough curves from the fixed-bed system is important in facility design and operation (Kanematsu et al., 2012; Yan et al., 2015). The column parameters are summarized in Table 1. Fig. 7a illustrates an effluent history of one fixed-bed column packed with the polyampholyte hydrogel. The $\mathrm{pH}$ values of the feed solutions were adjusted to 5.0. The metal-adsorbed hydrogel column was also eluted with $0.1 \mathrm{M} \mathrm{HCl}$ solution and then the hydrogel sorbent was in turn washed with $0.1 \mathrm{M} \mathrm{NaOH}$ solution and deionized water for next cycle.

At the completion of column flow-through experiment by simulated effluent (FS1) with each metal ion concentration of $40 \mathrm{mg} / \mathrm{L}$ (Fig. 7b), the nearly perfect superposition of the breakthrough curves for $\mathrm{Pb}(\mathrm{II})$ and $\mathrm{Cd}(\mathrm{II})$ from FS1 in the 1st and 3rd cycles prove that the polyampholyte hydrogel sorbent could be employed for repeated use with negligible sorption capacity loss. Before a $1 \%$ breakthrough of target metal ions in the 3rd cycle, the treatment volumes reach $192 \mathrm{BV}(2172 \mathrm{~mL})$ for $\mathrm{Pb}(\mathrm{II})$ and $168 \mathrm{BV}$ $(1900 \mathrm{~mL})$ for $\mathrm{Cd}(\mathrm{II})$. The outstanding reusability of the polyampholyte hydrogel should be attributed to its remarkable mechanical strength and efficient desorption/regeneration ability. Fig. 7c illustrates the desorption history of $\mathrm{Pb}(\mathrm{II})$ and $\mathrm{Cd}(\mathrm{II})$ preloaded onto the polyampholyte hydrogel. It shows that the sorbed $\mathrm{Pb}(\mathrm{II})$ and $\mathrm{Cd}(\mathrm{II})$ could be entirely eluted with only $3 \mathrm{BV}(34 \mathrm{~mL})$ of $\mathrm{HCl}$ solution. In other words, $2172 \mathrm{~mL} \mathrm{Pb(II)}$ or $1900 \mathrm{~mL} \mathrm{Cd(II)}$ wastewater can be treated with producing only $34 \mathrm{~mL}$ eluent. So the fixed-bed column systems can be featured by efficiency, flexibility and re-utilizing. The polyampholyte hydrogel presents its potential applicability for highly efficient removal of heavy metals from actual contaminated waters.

Fig. 7d shows a significantly retarded breakthrough of $\mathrm{Pb}(\mathrm{II})$
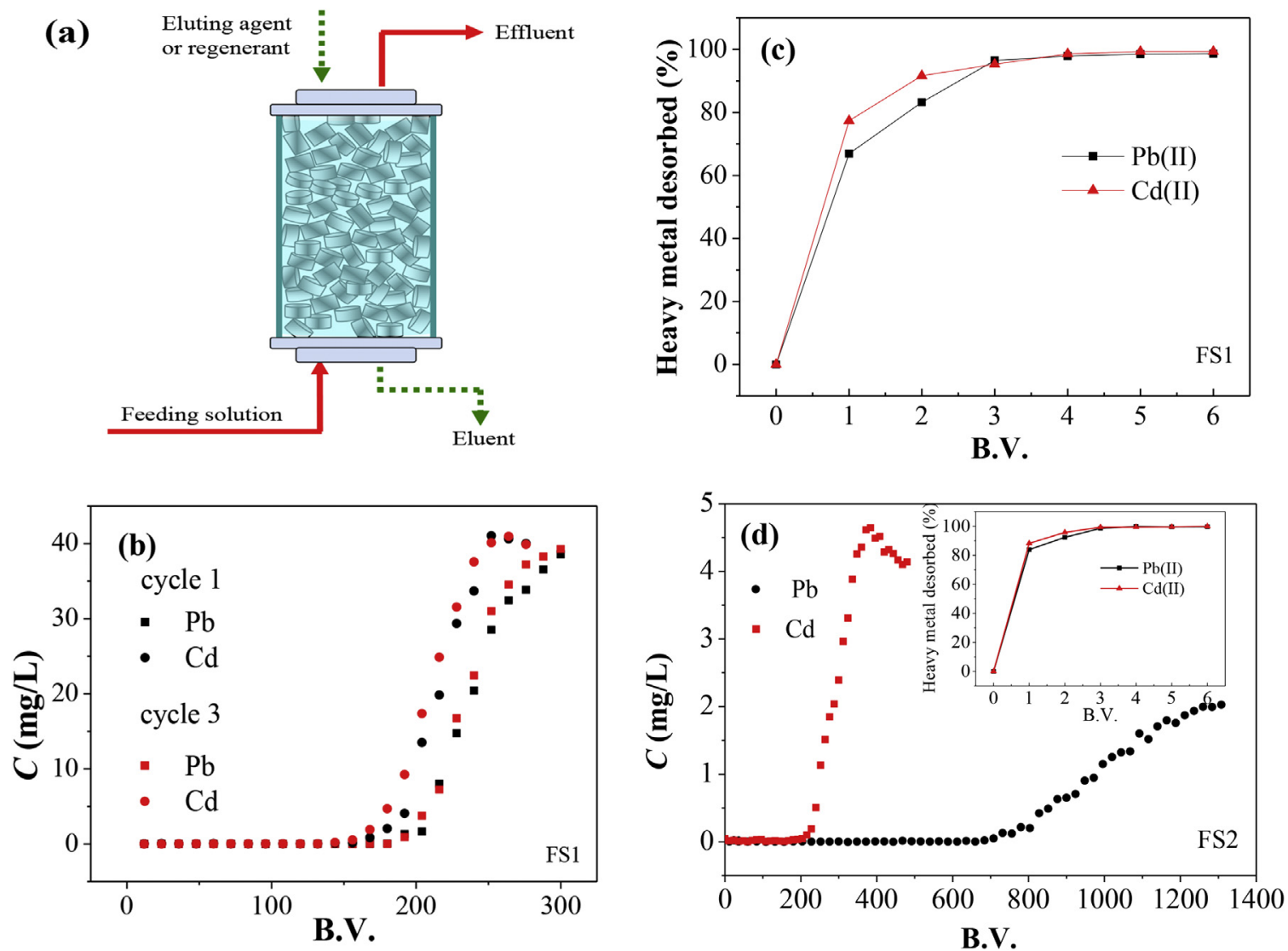

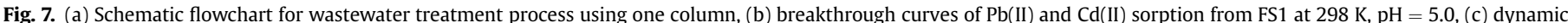

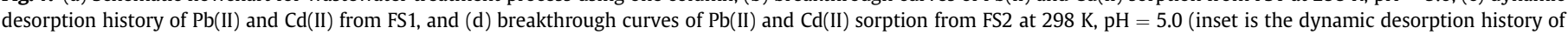
$\mathrm{Pb}(\mathrm{II})$ and $\mathrm{Cd}(\mathrm{II})$ from FS2 on the polyampholyte hydrogel). $1 \mathrm{BV}$ is $11.31 \mathrm{~mL}$. 
(a)

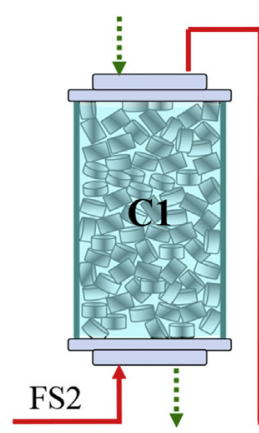

Eluent
Eluting agent or regenerant

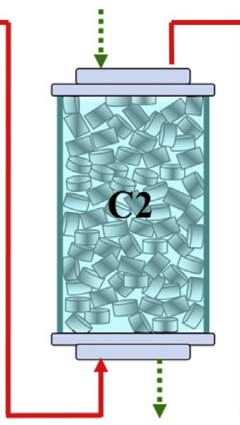

Eluent

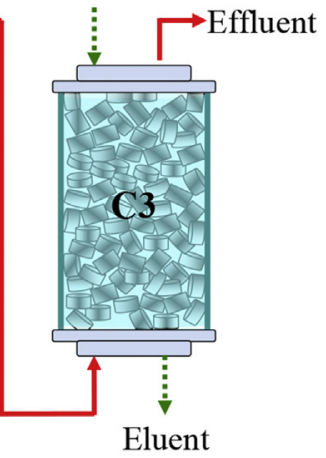

(b)

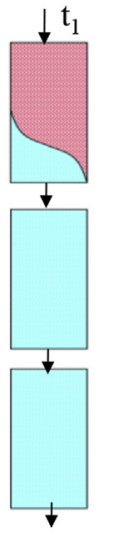

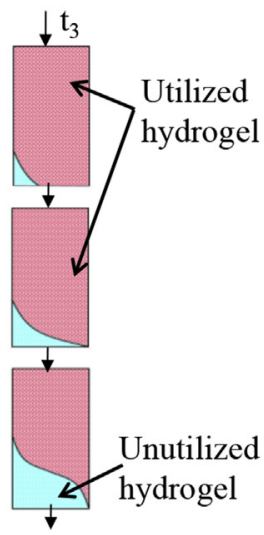

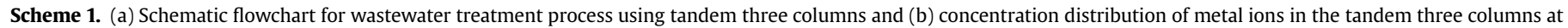
different time.

and $\mathrm{Cd}(\mathrm{II})$ sorption from actual industrial effluent (FS2) onto the polyampholyte hydrogel. Before a $1 \%$ breakthrough of target metal ions, the treatment volume is about $684 \mathrm{BV}(7736 \mathrm{~mL})$ for $\mathrm{Pb}(\mathrm{II})$ and $200 \mathrm{BV}(2262 \mathrm{~mL}$ ) for Cd(II) when the effluent concentrations satisfy the regulatory requirements. The sorbed $\mathrm{Pb}(\mathrm{II})$ and $\mathrm{Cd}(\mathrm{II})$ can be entirely eluted with only $3 \mathrm{BV}(34 \mathrm{~mL})$ of $\mathrm{HCl}$ solution (inset in Fig. 7d). It is observed that the effluent concentration $(C)$ in excess of a unity on the breakthrough curve for $\mathrm{Cd}(\mathrm{II})$ sorption is attributed to the chromatographic elution effect of $\mathrm{Pb}$ (II) (the adsorbed Cd(II) was exchanged with $\mathrm{Pb}(\mathrm{II})$ ) (Pan et al., 2010). If the treatment volume is controlled below $200 \mathrm{BV}$, both $\mathrm{Pb}(\mathrm{II})$ and $\mathrm{Cd}(\mathrm{II})$ in the actual industrial effluent can be effectively removed. Although the concentrations of $\mathrm{Pb}(\mathrm{II})$ and $\mathrm{Cd}(\mathrm{II})$ in the effluent are qualified, $\mathrm{Zn}, \mathrm{Mn}, \mathrm{Ni}$ and $\mathrm{Cu}$ are still not qualified. So the wastewater treatment process using tandem three columns was further investigated under the same parameters as one fixed-bed column (Scheme 1a).

Fig. 8 shows the results of FS2 treatment using tandem three columns. Before a $1 \%$ breakthrough of target metal ions, the treatment volumes reach $924 \mathrm{BV}(31,351 \mathrm{~mL})$ for $\mathrm{Pb}(\mathrm{II})$ and $250 \mathrm{BV}$ (8483 mL) for Cd(II) (Fig. 8a). Thus it can be seen that if the treatment volume is controlled below $250 \mathrm{BV}$, both $\mathrm{Pb}(\mathrm{II})$ and $\mathrm{Cd}(\mathrm{II})$ in the actual industrial effluent can be effectively removed. It should be noted that the treatment volumes of the tandem three columns are 4.05 or 3.75 times higher than those of single column for $\mathrm{Pb}(\mathrm{II})$ or $\mathrm{Cd}(\mathrm{II})$. It can be explained by the fact that the operation in this manner (via valves) allows more complete use of the hydrogel for removal of metal ions because sufficient contact time facilitates more mass transfer onto the surface and into the pores so that more metal ions can be adsorbed through tandem three columns (Scheme 1b) (Kanematsu et al., 2012). Experiment results also reveal that when the treatment volume is controlled below $209.3 \mathrm{BV}(7103 \mathrm{~mL})$, all metal ions in the actual industrial effluent can be effectively removed $(<0.01 \mathrm{mg} / \mathrm{L})$.

The desorption history of $\mathrm{Pb}(\mathrm{II})$ and $\mathrm{Cd}(\mathrm{II})$ on the polyampholyte hydrogel illustrates that the sorbed $\mathrm{Pb}(\mathrm{II})$ and $\mathrm{Cd}(\mathrm{II})$ can be entirely eluted with approximately $4 \mathrm{BV}(136 \mathrm{~mL})$ of $\mathrm{HCl}$ solution (Fig. 8b). Compared with the traditional high density slurry (HDS) process with large amount of sludge, the proposed process would be expected to produce only a small amount of sludge. According to the total bed contact time ( $15 \mathrm{~min})$, it can be inferred that the tandem three-column process (total volume of $33.93 \mathrm{~mL}$ ) can treat $96 \mathrm{BV}(3257 \mathrm{~mL}$ ) actual industrial effluent per day. For so small scale column, the treatment capacity is very encouraging.

\section{Conclusions}

In this study, a polyampholyte hydrogel was well designed and prepared via a simple radical polymerization procedure. The polyampholyte hydrogel sorbent could be easily regenerated and highly reused. The sorption capacities were as high as $216.1 \mathrm{mg} / \mathrm{g}$ for $\mathrm{Pb}(\mathrm{II})$ and $153.8 \mathrm{mg} / \mathrm{g}$ for $\mathrm{Cd}(\mathrm{II})$. The adsorption could be conducted in a wide $\mathrm{pH}$ range of 3-6 and the equilibrium fast reached in $30 \mathrm{~min}$. The polyampholyte hydrogel was effective in removing heavy metals from actual industrial effluent with large treatment capacity, producing a small quantity of eluent. This wok opens a new window to develop high performance sorbents for the removal
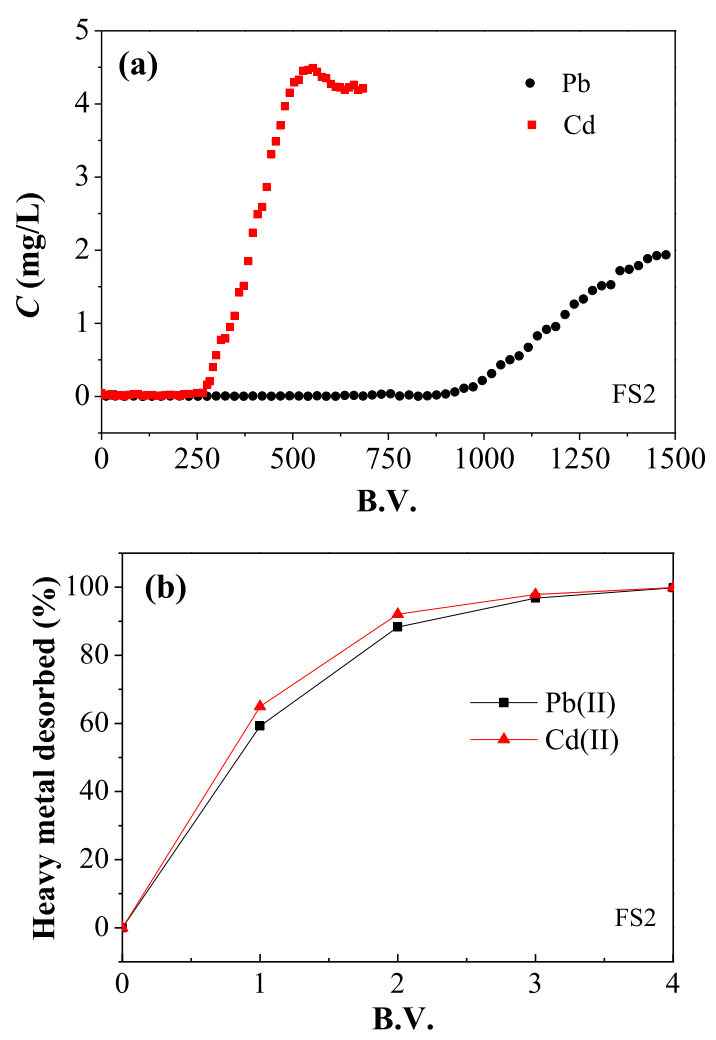

Fig. 8. (a) Breakthrough curves of $\mathrm{Pb}(\mathrm{II})$ and $\mathrm{Cd}(\mathrm{II})$ sorption from FS2 in the tandem three columns, (b) dynamic desorption history of $\mathrm{Pb}(\mathrm{II})$ and $\mathrm{Cd}(\mathrm{II})$ from FS2. 1 BV is $33.93 \mathrm{~mL}$. 
of heavy metal ions from wastewater.

\section{Acknowledgments}

This work was supported by Hunan Provincial Natural Science Foundation of China (14JJ1015), the National Natural Science Foundation of China (51178173, 51238002, 51272099, 51378187, and 51478171), and Program for Innovation Research Team in University (IRT1238).

\section{Appendix A. Supplementary data}

Supplementary data related to this article can be found at http:// dx.doi.org/10.1016/j.watres.2015.11.053.

\section{References}

Ali, I., 2012. New generation adsorbents for water treatment. Chem. Rev. 112 (10), 5073-5091.

Bian, Z.F., Miao, X.X., Lei, S.Q., Chen, S.E., Wang, W.F., Struthers, S., 2012. The challenges of reusing mining and mineral-processing wastes. Science 337 (6095), $702-703$.

Calvert, P., 2009. Hydrogels for soft machines. Adv. Mater 21 (7), 743-756.

Cao, C.Y., Qu, J., Yan, W.S., Zhu, J.F., Wu, Z.Y., Song, W.G., 2012. Low-cost synthesis of flowerlike $\alpha-\mathrm{Fe}_{2} \mathrm{O}_{3}$ nanostructures for heavy metal ion removal: adsorption property and mechanism. Langmuir 28 (9), 4573-4579.

Chen, Q., Zhu, L., Zhao, C., Wang, Q.M., Zheng, J., 2013. A robust, one-pot synthesis of highly mechanical and recoverable double network hydrogels using thermoreversible sol-gel polysaccharide. Adv. Mater 25 (30), 4171-4176.

Dastgheib, S.A., Rockstraw, D.A., 2002. A model for the adsorption of single metal ion solutes in aqueous solution onto activated carbon produced from pecan shells. Carbon 40 (11), 1843-1851.

Du, G.L., Gao, G.R., Hou, R.X., Cheng, Y.J., Chen, T., Fu, J., Fei, B., 2014. Tough and fatigue resistant biomimetic hydrogels of interlaced self-assembled conjugated polymer belts with a polyelectrolyte network. Chem. Mater 26 (11), 3522-3529.

Genç-Fuhrman, H., Tjell, J.C., McConchie, D., 2004. Adsorption of arsenic from water using activated neutralized red mud. Environ. Sci. Technol. 38 (8), 2428-2434.

Gonçlves, G. Marques, P.A., Barros-Timmons, A., Bdkin, I., Singh, M.K., Emami, N., Grácio, J., 2010. Graphene oxide modified with PMMA via ATRP as a reinforcement filler. J. Mater. Chem. 20 (44), 9927-9934.

Guo, X.Y., Du, B., Wei, Q., Yang, J., Hu, L.H., Yan, L.G., Xu, W.Y., 2014. Synthesis of amino functionalized magnetic graphenes composite material and its application to remove $\mathrm{Cr}(\mathrm{VI}), \mathrm{Pb}(\mathrm{II}), \mathrm{Hg}(\mathrm{II}), \mathrm{Cd}(\mathrm{II})$ and $\mathrm{Ni}(\mathrm{II})$ from contaminated water. J. Hazard. Mater 278, 211-220.

Gurgel, L.V.A., Gil, L.F., 2009. Adsorption of $\mathrm{Cu}$ (II), Cd (II) and $\mathrm{Pb}$ (II) from aqueous single metal solutions by succinylated twice-mercerized sugarcane bagasse functionalized with triethylenetetramine. Water Res. 43 (18), 4479-4488.

Hadi, P., Barford, J., McKay, G., 2013. Toxic heavy metal capture using a novel electronic waste-based material-mechanism, modeling and comparison. Environ. Sci. Technol. 47 (15), 8248-8255.

Huang, T., Xu, H.G., Jiao, K.X., Zhu, L.P., Brown, H.R., Wang, H.L., 2007. A novel hydrogel with high mechanical strength: a macromolecular microsphere composite hydrogel. Adv. Mater 19 (12), 1622-1626.

Huang, Z.H., Zheng, X., Lv, W., Wang, M., Yang, Q.H., Kang, F., 2011. Adsorption of lead(II) ions from aqueous solution on low-temperature exfoliated graphene nanosheets. Langmuir 27 (12), 7558-7562.

Jin, L.Y., Zhang, G.M., Tian, H.F., 2014a. Current state of sewage treatment in China. Water Res. 66, 85-98.

Jin, Y.J., Liu, F., Shan, C., Tong, M.P., Hou, Y.L., 2014b. Efficient bacterial capture with amino acid modified magnetic nanoparticles. Water Res. 50, 124-134.

Kanematsu, M., Young, T.M., Fukushi, K., Green, P.G., Darby, J.L., 2012. Individual and combined effects of water quality and empty bed contact time on $\mathrm{As}(\mathrm{V})$ removal by a fixed-bed iron oxide adsorber: implication for silicate precoating. Water Res. 46 (16), 5061-5070.

Kudaibergenov, S., Ciferri, A, 2007. Natural and synthetic polyampholytes, functions and applications. Macromol. Rapid Commun. 28 (20), 1969-1986.

Li, J., Zhang, S.W., Chen, C.G., Zhao, G.X., Yang, X., Li, J.X., Wang, X.K., 2012. Removal of $\mathrm{Cu}$ (II) and fulvic acid by graphene oxide nanosheets decorated with $\mathrm{Fe}_{3} \mathrm{O}_{4}$ nanoparticles. ACS Appl. Mater. Interfaces 4 (9), 4991-5000.

Liang, X.F., Xu, Y.M., Sun, G.H., Wang, L., Sun, Y.B., Sun, Y., Qin, X., 2011. Preparation and characterization of mercapto functionalized sepiolite and their application for sorption of lead and cadmium. Chem. Eng. J. 174 (1), 436-444.

Liu, R.Q., Liang, S.M., Tang, X.Z., Yan, D., Li, X.F., Yu, Z.Z., 2012. Tough and highly stretchable graphene oxide/polyacrylamide nanocomposite hydrogels. J. Mater. Chem. 22 (28), 14160-14167.

Liu, X.M., Song, Q.J., Tang, Y., Li, W.L., Xu, J.M., Wu, J.M., Wang, F., Brookes, P.C., 2013.
Human health risk assessment of heavy metals in soil-vegetable system: a multi-medium analysis. Sci. Total Environ. 463, 530-540.

Lowry, G.V., Gregory, K.B., Apte, S.C., Lead, J.R., 2012. Transformations of nanomaterials in the environment. Environ. Sci. Technol. 46 (13), 6893-6899.

Luo, S.L., Li, X.J., Chen, L., Chen, J.L., Wan, Y., Liu, C.B., 2014a. Layer-by-layer strategy for adsorption capacity fattening of endophytic bacterial biomass for highly effective removal of heavy metals. Chem. Eng. J. 239, 312-321.

Luo, S.L., Xu, X.L., Zhou, G.Y., Liu, C.B., Tang, Y.H., Liu, Y.T., 2014b. Amino siloxane oligomer-linked graphene oxide as an efficient adsorbent for removal of $\mathrm{Pb}(\mathrm{II})$ from wastewater. J. Hazard. Mater 274, 145-155.

Marcano, D.C., Kosynkin, D.V., Berlin, J.M., Sinitskii, A., Sun, Z.Z., Slesarev, A., Alemany, L.B., Lu, W., Tour, J.M., 2010. Improved synthesis of graphene oxide. ACS Nano 4 (8), 4806-4814.

Mawad, D., Stewart, E., Officer, D.L., Romeo, T., Wagner, P., Wagner, K., Wallace, G.G. 2012. A single component conducting polymer hydrogel as a scaffold for tissue engineering. Adv. Funct. Mater 22 (13), 2692-2699.

Nakajima, T., Sato, H., Zhao, Y., Kawahara, S., Kurokawa, T., Sugahara, K., Gong, J.P., 2012. A universal molecular stent method to toughen any hydrogels based on double network concept. Adv. Funct. Mater 22 (21), 4426-4432.

Ozay, O., Ekici, S., Baran, Y., Aktas, N., Sahiner, N., 2009. Removal of toxic metal ions with magnetic hydrogels. Water Res. 43 (17), 4403-4411.

Pan, B.J., Qiu, H., Pan, B.C., Nie, G.Z., Xiao, L.L., Lv, L., Zhang, W.M., Zhang, Q.X., Zheng, S.R., 2010. Highly efficient removal of heavy metals by polymersupported nanosized hydrated Fe(III) oxides: behavior and XPS study. Water Res. 44, 815-824.

Shibayama, M., 2012. Structure-mechanical property relationship of tough hydrogels. Soft Matter 8 (31), 8030-8038.

Sun, J.Y., Zhao, X.H., Illeperuma, W.R., Chaudhuri, O., Oh, K.H., Mooney, D.J. Vlassak, J.J., Suo, Z., 2012. Highly stretchable and tough hydrogels. Nature 489 (7414), 133-136.

Sun, T.L., Kurokawa, T., Kuroda, S., Ihsan, A.B., Akasaki, T., Sato, K., Haque, M.A. Nakajima, T., Gong, J.P., 2013a. Physical hydrogels composed of polyampholytes demonstrate high toughness and viscoelasticity. Nat. Mater 12 (10), 932-937.

Sun, Y.B., Shao, D.D., Chen, C.L., Yang, S.B., Wang, X.K., 2013b. Highly efficient enrichment of radionuclides on graphene oxide-supported polyaniline. Environ. Sci. Technol. 47 (17), 9904-9910.

Tamura, K., Kogure, T., Watanabe, Y., Nagai, C., Yamada, H., 2014. Uptake of cesium and strontium ions by artificially altered phlogopite. Environ. Sci. Technol. 48 (10), 5808-5815.

Tofighy, M.A., Mohammadi, T., 2011. Adsorption of divalent heavy metal ions from water using carbon nanotube sheets. J. Hazard. Mater 185 (1), 140-147.

Wang, L., Zhang, J., Zhao, R., Li, Y., Li, C., Zhang, C.L., 2010a. Adsorption of Pb(II) on activated carbon prepared from polygonum orientale Linn.: kinetics, isotherms, pH, and ionic strength studies. Bioresour. Technol. 101 (15), 5808-5814.

Wang, Q.G., Mynar, J.L., Yoshida, M., Lee, E., Lee, M., Okuro, K., Kinbara, K., Aida, T., 2010b. High-water-content mouldable hydrogels by mixing clay and a dendritic molecular binder. Nature 463 (7279), 339-343.

Wu, N.M., Li, Z.K., 2013. Synthesis and characterization of poly (HEA/MALA) hydrogel and its application in removal of heavy metal ions from water. Chem. Eng. J. 215, 894-902.

Wu, N., Wei, H.H., Zhang, L.Z., 2012. Efficient removal of heavy metal ions with biopolymer template synthesized mesoporous titania beads of hundreds of micrometers size. Environ. Sci. Technol. 46, 419-425.

Xu, R., Zhou, G.Y., Tang, Y.H., Chu, L., Liu, C.B., Zeng, Z.B., Luo, S.L., 2015. New double network hydrogel adsorbent: highly efficient removal of Cd(II) and $\mathrm{Mn}$ (II) ions in aqueous solution. Chem. Eng. J. 275, 179-188.

Yan, L., Huang, Y.Y., Cui, J.L., Jing, C.Y., 2015. Simultaneous As(III) and Cd removal from copper smelting wastewater using granular $\mathrm{TiO}_{2}$ columns. Water Res. 68 , $572-579$.

Yang, G.X., Jiang, H., 2014. Amino modification of biochar for enhanced adsorption of copper ions from synthetic wastewater. Water Res. 48, 396-405.

Yin, H.Y., Akasaki, T., Sun, T.L., Nakajima, T., Kurokawa, T., Nonoyama, T., Taira, T., Saruwatare, Y., Gong, J.P., 2013. Double network hydrogels from polyzwitterions: high mechanical strength and excellent anti-biofouling properties. J. Mater. Chem. B 1 (30), 3685-3693.

Yu, J.X., Tong, M., Sun, X.M., Li, B.H., 2008. Enhanced and selective adsorption of $\mathrm{Pb}^{2+}$ and $\mathrm{Cu}^{2+}$ by EDTAD-modified biomass of baker's yeast. Bioresour. Technol. 99 (7), 2588-2593.

Zhao, G.X., Li, J.X., Ren, X.M., Chen, C.G., Wang, X.K., 2011. Few-layered graphene oxide nanosheets as superior sorbents for heavy metal ion pollution management. Environ. Sci. Technol. 45 (24), 10454-10462.

Zhao, J., Wang, Z.Y., White, J.C., Xing, B.S., 2014. Graphene in the aquatic environment: adsorption, dispersion, toxicity and transformation. Environ. Sci. Technol. 48 (17), 9995-10009.

Zhou, G.Y., Liu, C.B., Tang, Y.H., Luo, S.L., Zeng, Z.B., Liu, Y.T., Xu, R., Chu, L., 2015 Sponge-like polysiloxane-graphene oxide gel as a highly efficient and renewable adsorbent for lead and cadmium metals removal from wastewater. Chem. Eng. J. 280, 275-282.

Zhu, Y.H., Hu, J., Wang, J.L., 2012. Competitive adsorption of $\mathrm{Pb}(\mathrm{II}), \mathrm{Cu}(\mathrm{II})$ and $\mathrm{Zn}$ (II) onto xanthate-modified magnetic chitosan. J. Hazard. Mater 221-222, 155-161. 